\title{
Synthesis of Glycopolymer Gold Nanoparticles Decorated with Oligosaccharides via a Protecting-group-free Process and Their Specific Recognition by Lectins
}

\author{
Tomonari Tanaka*, Hiroyuki Fukumoto and Hideki Ishitani \\ Department of Biobased Materials Science, Graduate School of Science and Technology, Kyoto Institute of Technology, \\ Matsugasaki, Sakyo-ku, Kyoto 606-8585, Japan \\ * Corresponding author: e-mail: t-tanaka@kit.ac.jp
}

\begin{abstract}
Glycopolymers with various pendant oligosaccharides were synthesized from free saccharides without protection of the saccharide hydroxy and carboxy groups. The strategy involved direct anomeric azidation of the free saccharides, copper-catalyzed azide-alkyne cycloaddition, and reversible addition-fragmentation chain transfer polymerization using the glycomonomers and trithiocarbonate derivative as a chain transfer agent. After reducing the trithiocarbonate terminal group on the polymer backbone, the resulting thiol-terminated glycopolymers were immobilized on gold nanoparticles via Au-S bound formation. The glycopolymer-decorated gold nanoparticles in aqueous suspension were specifically recognized by the corresponding lectin, with no measurable nonspecific binding.

Key words: maltooligosaccharide, sialyloligosaccharide, protecting-group-free, RAFT polymerization, protein recognition
\end{abstract}

\section{INTRODUCTION}

Oligosaccharides have received much attention from scientists working in diverse fields such as biochemistry, polymer chemistry, and materials science. Although the interactions between saccharide and protein are generally weak, they are amplified by multivalent forms of saccharides. Such multivalent saccharides give rise to the "glycocluster effect"[1,2] underlying various biological processes. Glyconanoparticles, whose surfaces are decorated with saccharides,[3-8] form artificial glycoclusters and amplify the saccharide signals of natural ligands, as well as of glycodendrimers [9-11] and glycopolymers comprising a synthetic polymer with pendant saccharides. Glycopolymer-decorated nanoparticles composed of a metal such as gold[12-15] or of quantum dots[16,17] have been reported to form artificial glycoclusters, and this approach typically uses smaller saccharides such as mono- and disaccharides. However, little has been reported regarding the preparation of nanoparticles decorated with longer chain oligosaccharides and sialyl oligosaccharides.

We recently reported the protecting-group-free synthesis of glycomonomers from free saccharides via the direct synthesis of $\beta$-glycosyl azides and subsequent copper-catalyzed azide-alkyne cycloaddition (CuAAC).[18,19] We followed the reversible addition-fragmentation chain transfer (RAFT) polymerization reaction using the resulting glycomonomers to obtain glycopolymers. In this paper, we report the decoration of gold nanoparticles (GNPs) using glycopolymers bearing oligosaccharides, and investigate the binding properties of lectins towards the glycopolymer-decorated GNPs.

\section{RESULTS AND DISCUSSION}

2.1 Synthesis of glycopolymers from free saccharides Glycopolymers bearing oligosaccharides were synthesized from the corresponding free saccharides by a protecting-group-free procedure via a RAFT polymerization technique using glycomonomers (Fig. 1). Glycomonomers with triazole-linked acrylamide (AAm) at the anomeric position were synthesized via direct anomeric azidation of free saccharides and subsequent CuAAC. $\beta$-Glycosyl azides were directly synthesized from the free maltooligosaccharides maltose $\left(\mathrm{Glc}_{2}\right)$, maltotriose $\left(\mathrm{Glc}_{3}\right)$, maltopentaose $\left(\mathrm{Glc}_{5}\right)$, and maltoheptaose $\quad\left(\mathrm{Glc}_{7}\right)$ using 2-chloro-1,3-dimethylimidazolinium chloride (DMC), sodium azide, and $N, N$-diisopropylethylamine (DIPEA) in water at $0{ }^{\circ} \mathrm{C}[20]$. The resulting $\beta$-glycosyl azides were reacted in aqueous dimethylformamide (DMF) at room temperature with $N$-propargyl acrylamide in the presence of a catalytic amount of copper(II) sulfate pentahydrate $\left(\mathrm{CuSO}_{4} \cdot 5 \mathrm{H}_{2} \mathrm{O}\right)$, L-ascorbic acid sodium salt (AscNa), and tris[(1-benzyl-1H-1,2,3-triazol-4-yl)-methyl]amine (TBTA). AAm derivatives carrying triazole-linked oligosaccharides were obtained starting from the corresponding free saccharides without the use of any protecting group. The glycomonomers were subjected to RAFT copolymerization with AAm in dimethyl sulfoxide (DMSO) to obtain glycopolymers using 2,2'-azobis(4-methoxy-2,4-dimethylvaleronitrile) (V-70) and 2-(benzylsulfanylthiocarbonylsulfanyl) ethanol (BTSE) as an initiator and chain transfer agent, respectively. Table I summarizes the results of the RAFT copolymerization reactions using glycomonomers carrying a maltooligosaccharide with AAm. The glycopolymers were purified by dialysis against water. The maltooligosaccharide-containing glycomonomers $\mathrm{Glc}_{2} \mathrm{AAm}$, Glc $\mathrm{c}_{3} \mathrm{AAm}$, Glc 5 AAm, and Glc 7 AAm provided the corresponding desired glycopolymers PolyGlc $2 A A m$, PolyGlc 3 AAm, PolyGlc 5 AAm, and PolyGlc 7 AAm, with low dispersity $\left(M_{\mathrm{w}} / M_{\mathrm{n}}<1.2\right)$. The saccharide unit ratios in the product polymers were 


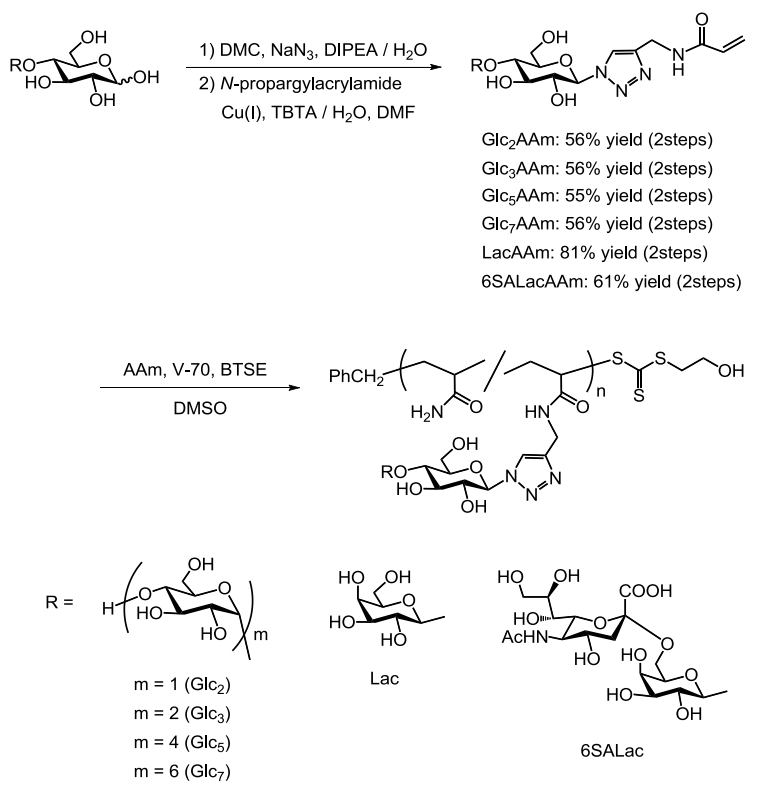

Fig. 1 Synthesis of glycopolymers from free saccharides.

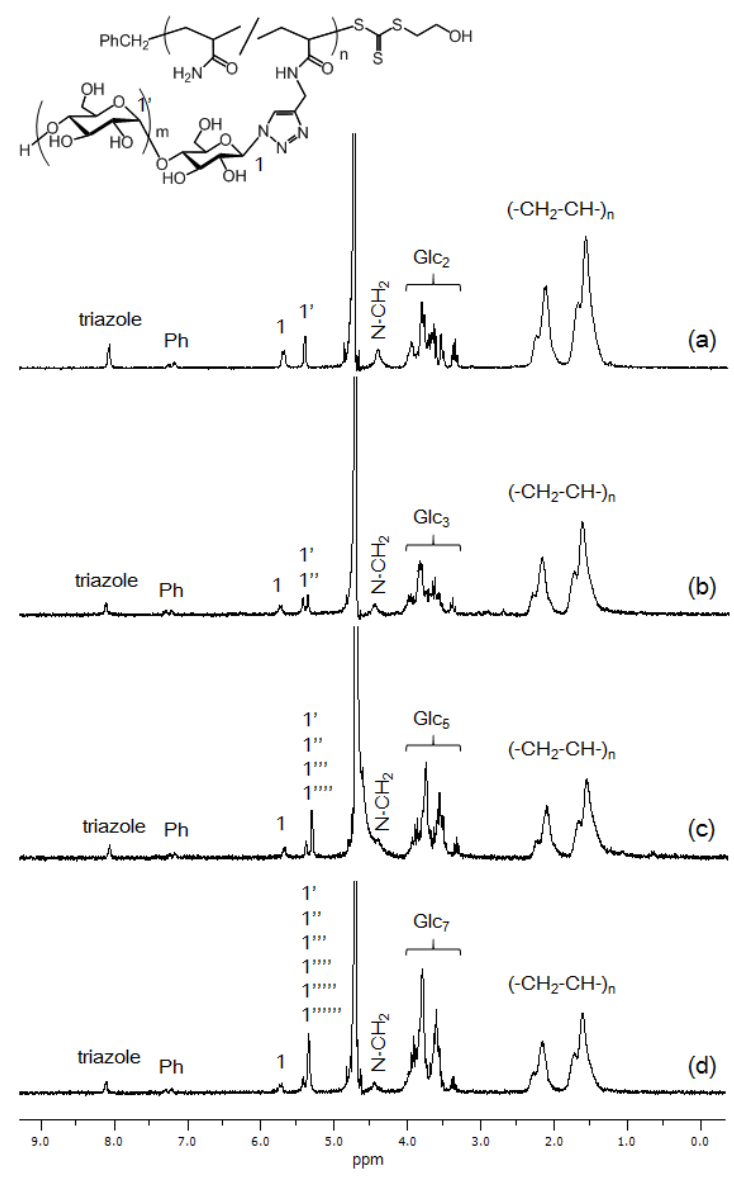

Fig. $2{ }^{1} \mathrm{H}$ NMR spectra of (a) PolyGlc $2 \mathrm{AAm}$, (b) PolyGlcs AAm, (c) PolyGlc5AAm, and (d) $\mathrm{PolyGlc}_{7} \mathrm{AAm}$ in $\mathrm{D}_{2} \mathrm{O}$.

slightly lower $(4.3-7.2 \%)$ than the glycomonomer ratio in the feed $(10 \%)$, suggesting that steric hindrance by the saccharide moiety affected the reactivity of the glycomonomer. The ${ }^{1} \mathrm{H}$ NMR spectra of the glycopolymers showed a polymer backbone, the anomer of the saccharide, and triazole protons at 1.3-2.4, 5.7, and $8.1 \mathrm{ppm}$, respectively (Fig. 2).

Table I Synthesis of glycopolymers by RAFT copolymerization using glycomonomers.

\begin{tabular}{lllll}
\hline $\begin{array}{l}\text { Glyco } \\
\text { monomer }\end{array}$ & $\begin{array}{l}\text { Yield } \\
(\%)^{\mathrm{a}}\end{array}$ & $\begin{array}{l}M_{\mathrm{n}} \\
(\mathrm{g} / \mathrm{mol})^{\mathrm{b}}\end{array}$ & $M_{\mathrm{w}} / M_{\mathrm{n}}{ }^{\mathrm{c}}$ & $\begin{array}{l}\text { Sacchari } \\
\text { de ratio } \\
(\%))^{\mathrm{b}, \mathrm{d}}\end{array}$ \\
\hline Glc $_{2} \mathrm{AAm}$ & 74 & 15200 & 1.14 & 7.2 \\
Glc $_{3} \mathrm{AAm}$ & 56 & 11300 & 1.18 & 4.3 \\
Glc5AAm & 47 & 16000 & 1.17 & 6.3 \\
Glc7AAm & 50 & 13800 & 1.17 & 5.1 \\
\hline
\end{tabular}

${ }^{a}$ Isolated yield of glycopolymer. ${ }^{b}$ Determined by ${ }^{1} \mathrm{H}$ NMR. ${ }^{c}$ Determined by GPC. ${ }^{d}$ Ratio of glycomonomer unit in the polymer.

\subsection{Binding assay of glycopolymer-decorated GNPs}

The synthesized glycopolymers were immobilized on GNPs via Au-S bonds. Thiol-terminated glycopolymers were prepared by reducing the trithiocarbonate terminal group with sodium borohydride (Fig. 3). Following immobilization, the glycopolymer-immobilized GNPs could be suspended in aqueous media. The diameters of the glycopolymer-immobilized GNPs increased from $20-60 \mathrm{~nm}$ (before immobilization) to $40-100 \mathrm{~nm}$, as analyzed by dynamic light scattering (DLS) measurements (Fig. 4), indicating that the glycopolymers were successfully immobilized on the surface of the GNPs.

The ability of the saccharide moieties immobilized on GNPs to recognize lectins was investigated. Concanavalin A from Canavalia ensiformis (ConA) recognizes $\alpha$-glucosyl residues such as maltooligosaccharides. When ConA was added to PolyGlc 2 AAm-immobilized GNPs (PolyGlc 2 AAm-GNPs) dispersed in phosphate buffered saline (PBS), the absorbance was decreased and reached equilibrium immediately. The absorbance of the maximum absorption of GNPs (particle size: $40 \mathrm{~nm}$ ) that is, $530 \mathrm{~nm}$, gradually and significantly decreased with increasing concentration of ConA from 0 to $4000 \mathrm{nM}$ (Fig. 5c). On the other hand, the absorbance did not decrease when bovine serum albumin (BSA) was added
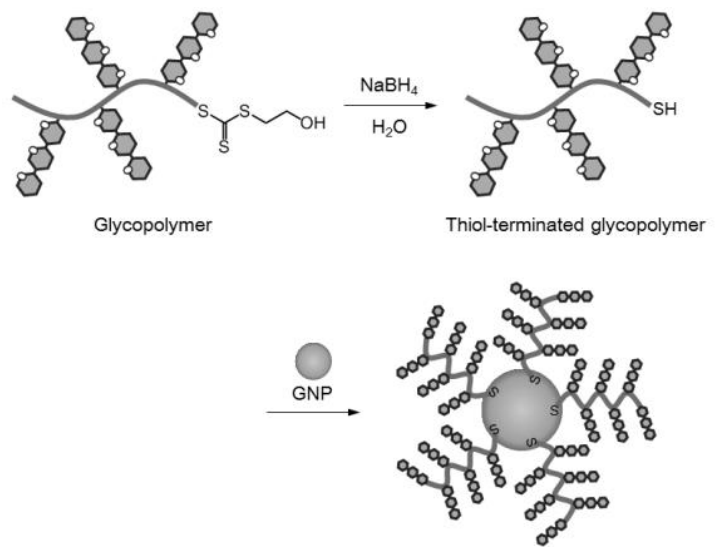

Fig. 3 Immobilization of glycopolymers on GNPs. 
(a)

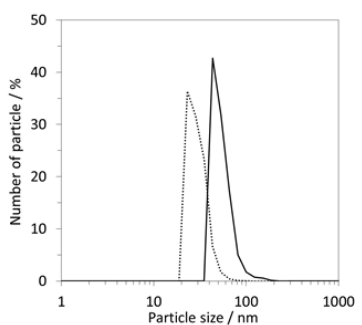

(c)

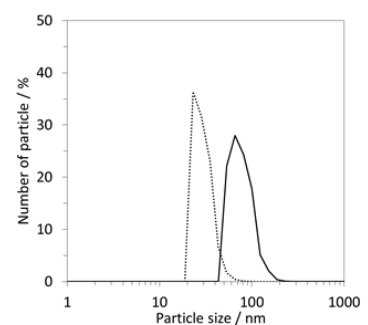

(e)

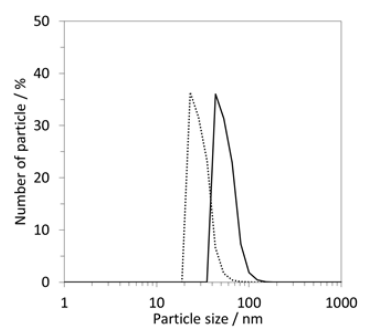

(b)

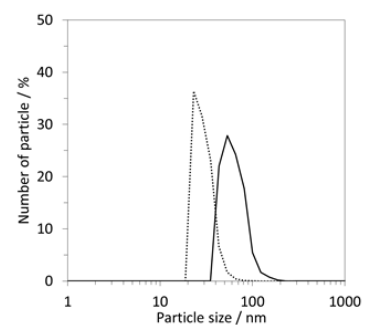

(d)

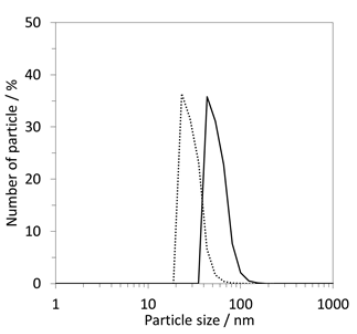

(f)

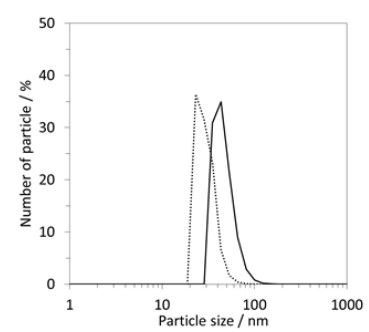

Fig. 4 DLS analysis of GNPs before (dotted line) and after (solid line) immobilization of glycopolymers (a) PolyGlc $2 \mathrm{AAm}$ (b) PolyGlc 3 AAm, (c) PolyGlc 5 AAm, (d) PolyGlc7AAm, (e) PolyLacAAm, (f) Poly6SALacAAm.

to the PolyGlc $2 \mathrm{AAm}-\mathrm{GNP}$ suspension as a control (Fig. 5a). In addition, ConA did not bind to polyacrylamide (PolyAAm)-immobilized GNPs lacking saccharides (Fig. $5 b)$. These results indicated that ConA induced the aggregation of PolyGlc2AAm-GNP due to lectin-saccharide interactions, and not because of its nonspecific adsorption on GNPs. For GNPs with other immobilized glycopolymers bearing maltooligosaccharides (PolyGlc 3 AAm, PolyGlc $_{5} \mathrm{AAm}$, and PolyGlc 7 AAm), the maximum absorption of the GNPs at $530 \mathrm{~nm}$ decreased with increasing concentration of ConA, similar to PolyGlc 2 AAm-GNP (Fig. 5d-f). Although the estimation of loading amount of glycopolymers on GNPs was not achieved because of extremely small experimental scale in microgram order, we discuss about the relation between saccharide ratio in glycopolymers and lectin recognition. The decreasing of absorbance at $530 \mathrm{~nm}$ using PolyGlc 2 AAm-GNP (saccharide unit ratio 7.2\%) was significantly more than that of using PolyGlc 3 AAm-GNP (saccharide unit ratio 4.3\%) with increasing concentration of ConA, suggesting that the ratio of glycomonomer unit in glycopolymer was important to be strongly recognized by lectins.

We previously reported the synthesis of glycopolymers bearing lactose (Lac) and 6'-sialyllactose (6SALac) by the same protecting-group-free process,
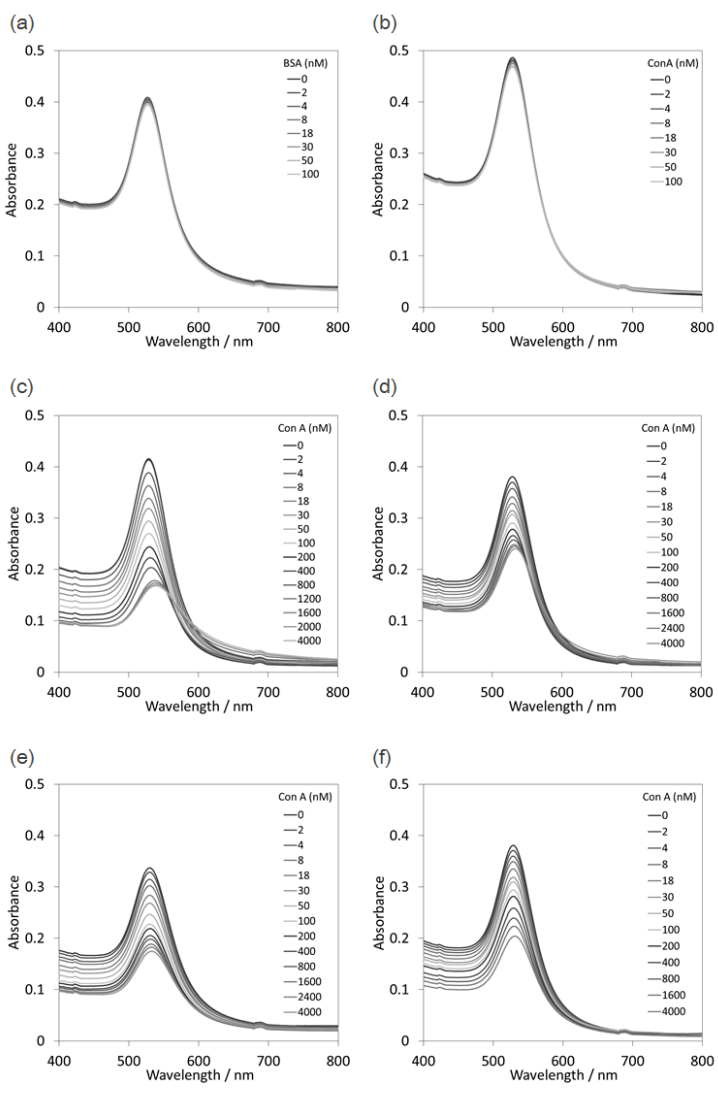

Fig. 5 UV-Vis glycopolymer-decorated PolyGlc 2 AAm-GNP PolyAAm-GNP
PolyGlc 2 AAm-GNP PolyGlc 3 AAm-GNP and ConA,
PolyGlc 5 AAm-GNP and ConA, PolyGlc 7 AAm-GNP and ConA.

spectra GNPs. BSA, ConA, and ConA, and ConA, ConA

starting from free Lac and 6SALac, and obtained corresponding glycopolymers PolyLacAAm $\left(M_{\mathrm{n}(\mathrm{NMR})}=\right.$ $\left.23000, M_{\mathrm{w}} / M_{\mathrm{n}}=1.16\right)$ and Poly6SALacAAm $\left(M_{\mathrm{n}(\mathrm{NMR})}=\right.$ $\left.23000, M_{\mathrm{w}} / M_{\mathrm{n}}=1.81\right)$.[18] These glycopolymers were immobilized on GNPs by Au-S bond formation after reducing the trithiocarbonate terminal group with sodium borohydride. When peanut agglutinin from Arachis hypogaea (PNA) was added to a suspension of PolyLacAAm-immobilized GNPs (PolyLacAAm-GNPs), the absorption at $530 \mathrm{~nm}$ gradually decreased with increasing concentration of PNA from 0 to $100 \mathrm{nM}$ due to specific recognition by PNA of the $\beta$-galactosyl residue (the nonreducing-end monosaccharide moiety in Lac) (Fig. 6a). When Sambucus sieboldiana agglutinin (SSA) was added to a suspension of Poly6SALacAAm-immobilized GNPs (Poly6SALacAAm-GNPs), the absorption at $530 \mathrm{~nm}$ gradually decreased with increasing concentration of SSA due to specific recognition by SSA of the $\alpha 2,6$-linked sialylgalactosyl residue (the nonreducing-end disaccharide moiety in 6SALac) (Fig. 6c). On the other hand, no decrease in absorption was observed when SSA and PNA were added to a suspension of PolyLacAAm-GNP and Poly6SALacAAm-GNP, respectively (Fig. $6 b$ and d). 
(a)

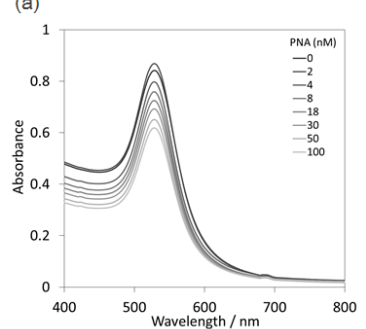

(b)

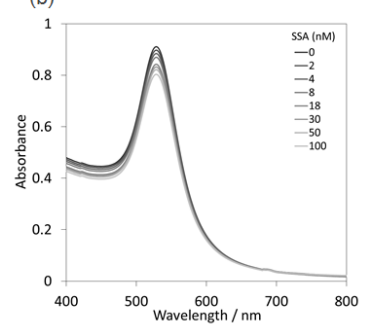

(c)
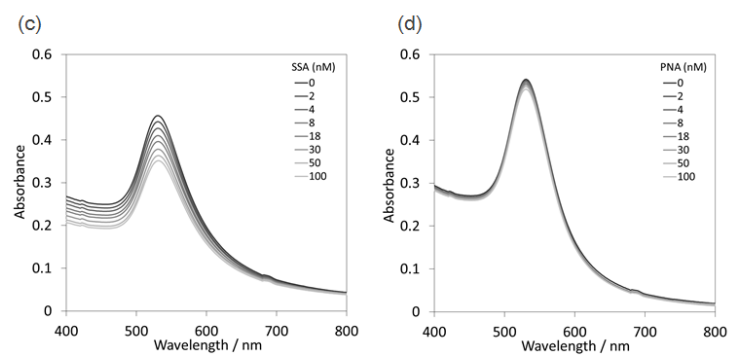

Fig. 6 UV-Vis

glycopolymer-decorated PolyLacAAm-GNP and

spectra

of

GNPs.

PNA,

PolyLacAAm-GNP and SSA,

Poly6SALacAAm-GNP and SSA,

Poly6SALacAAm-GNP and PNA.

Taken together, our results indicate that multivalent oligosaccharides on GNPs were specifically recognized by the corresponding lectins and there was no measureable nonspecific adsorption.

\section{CONCLUSION}

We succeeded in synthesizing glycopolymer GNPs decorated with oligosaccharides, including disaccharides, longer chain maltooligosaccharides, and a sialyltrisaccharide. The syntheses were achieved without the use of any protecting group for the saccharide hydroxy and carboxy groups. The glycopolymer-decorated GNPs were specifically recognized by the corresponding lectin in aqueous media in the absence of measurable nonspecific adsorption. These results indicate that the saccharide moieties on the glycopolymer-decorated GNPs amplified the saccharide-protein interactions due to the multivalency of the saccharides. This protecting-group-free synthetic methodology is applicable to not only mono- and disaccharides, but also to oligosaccharides with higher molecular weight and containing sialic acids. Consequently, this approach holds promise for the development of biosensors, such as for the detection of bio-related molecules, viruses, and toxins.

\section{EXPERIMENTAL SECTION}

\subsection{Materials}

Free $\mathrm{Glc}_{2}$ and $\mathrm{Glc}_{3}$ were purchased from Nacalai Tesque Inc. (Kyoto, Japan). Free $\mathrm{Glc}_{5}$ and $\mathrm{Glc}_{7}$ were purchased from Hayashibara Co., Ltd (Okayama, Japan). $\beta$-Glycosyl azides were synthesized from free saccharides using DMC and sodium azide in the presence of DIPEA according to literature.[20] $N$-Propargyl acrylamide was synthesized using acryloyl chloride and propargylamine in the presence of triethylamine according to the literature.[21] AAm was used after recrystallization from chloroform $/$ methanol $=$ 10/3. A chain transfer agent BTSE was synthesized using 2-mercaptoethanol, carbon disulfide, and benzyl bromide according to the literature.[22] GNP suspension (particle size: $40 \mathrm{~nm}, 0.0065 \mathrm{wt} \%$ ) was purchased from Tanaka Kikinzoku Kogyo K.K. (Tokyo, Japan). ConA was purchased from J-Oil Mills Inc. (Tokyo, Japan). PNA, SSA, and BSA were purchased from Wako Pure Chemical Industries (Osaka, Japan). All other reagents were commercially available and were used without further purification.

\subsection{Measurements}

NMR spectra were recorded using Bruker BioSpin AV-300 and AV-600 spectrometers. ESI mass spectra were recorded using a Bruker Daltonics micrOTOF-QIII spectrometer. GPC measurements were conducted using a system consisting of a JASCO PU-2089 pump, a CO-2065 column oven, an RI-2031 refractive index detector, and a Shodex OHpak SB-804 HQ $(8.0 \times 300$ $\mathrm{mm}$ ) column. $20 \mathrm{mM}$ phosphate buffer $(\mathrm{pH} 7.0)$ was used as the eluent at a flow rate of $0.5 \mathrm{~mL} / \mathrm{min}$ at $30^{\circ} \mathrm{C}$. Pullulan samples were used as standards. UV-Vis absorption spectra were recorded using a JASCO V-550 spectrometer at room temperature. DLS analyses were conducted in water using an Otsuka Electronics ELSZ-1000 with $667 \mathrm{~nm}$ at room temperature.

\subsection{Synthesis of $\beta$-glycosyl azides}

DMC was added to a mixture of free saccharide, DIPEA, and $\mathrm{NaN}_{3}$ in water, and the resulting mixture was stirred for $1 \mathrm{~h}$ at $0{ }^{\circ} \mathrm{C}$. After concentration of the reaction mixture under reduced pressure and addition of DMF, the solid was removed by filtration. The filtrate was concentrated under reduced pressure, then the residue was dissolved in water and extracted with dichloromethane. Finally, the product was purified by ion-exchange column chromatography (Amberlite IR-120B, previously activated with $1 \mathrm{M} \mathrm{NaOH}$, eluent; $\left.\mathrm{H}_{2} \mathrm{O}\right)$ and concentrated under reduced pressure to give a $\beta$-glycosyl azide.[18,20]

\subsection{Synthesis of glycomonomers}

$\boldsymbol{G l c}_{2} \boldsymbol{A} \boldsymbol{A} \boldsymbol{m}$. $N$-Propargyl acrylamide $(200 \mathrm{mg}, 1.83 \mathrm{mmol}$ ), $\mathrm{CuSO}_{4} \cdot 5 \mathrm{H}_{2} \mathrm{O}$ (100 mg, $\left.0.398 \mathrm{mmol}\right)$, AscNa (158 mg, $0.798 \mathrm{mmol}$ ), and TBTA (72 $\mathrm{mg}, 0.136 \mathrm{mmol})$ were added to a $50 \%$ DMF aqueous solution $(6.6 \mathrm{~mL})$ of $\beta$-maltosyl azide ( $460 \mathrm{mg}, 1.25 \mathrm{mmol}$ ), and the resulting mixture was stirred for $3.5 \mathrm{~h}$ at room temperature. After concentration of the reaction mixture under reduced pressure, the product was purified by silica gel column chromatography $\left(\mathrm{MeCN} / \mathrm{H}_{2} \mathrm{O}=5 / 1\right)$ and then stirring with metal scavenger $\left(\right.$ SiliaMetS ${ }^{\circledR}$ Imidazole, $1.08 \mathrm{~g}, 5$ equiv. for $\mathrm{Cu}$ ) overnight at room temperature. After removing of metal scavenger by filtration, the filtrate was concentrated under reduced pressure and freeze-dried to give $\mathrm{Glc}_{2} \mathrm{AAm}(434 \mathrm{mg}, 0.911 \mathrm{mmol}$, $73 \%) .{ }^{1} \mathrm{H}$ NMR $\left(600 \mathrm{MHz}, \mathrm{D}_{2} \mathrm{O}\right): \delta(\mathrm{ppm}) 8.08(\mathrm{~s}, 1 \mathrm{H}$, triazole), 6.24-6.13 (m, $2 \mathrm{H}$, vinyl), 5.72-5.67 (m, $2 \mathrm{H}$, vinyl and $\mathrm{H} 1), 5.41\left(\mathrm{~d}, 1 \mathrm{H}, J_{1}, 2,=3.6 \mathrm{~Hz}, \mathrm{H} 1{ }^{\prime}\right), 4.51$ (s, $\left.2 \mathrm{H}, \mathrm{N}-\mathrm{CH}_{2}\right), 3.96-3.35$ (m, 12H, Glc 2$) .{ }^{13} \mathrm{C}$ NMR (125 $\left.\mathrm{MHz}, \mathrm{D}_{2} \mathrm{O}\right): \delta(\mathrm{ppm}) 168.6(\mathrm{C}=\mathrm{O}), 144.9$ (triazole), 129.6 and 127.8 (2C, vinyl), 123.0 (triazole), 99.6 (C1'), 87.2 (C1), 77.5 (C4), 76.3 (C5), 75.8 (C5'), 72.82 and 72.75 (C3 and C3'), 72.1 (C2), 71.7 (C2'), 69.3 (C4'), 
60.5 and 60.4 (C6 and $\mathrm{C} 6$ '), $34.5\left(\mathrm{~N}-\mathrm{CH}_{2}\right)$. ESI MS: [M $+\mathrm{Na}]^{+}, \mathrm{M}=\mathrm{C}_{18} \mathrm{H}_{28} \mathrm{~N}_{4} \mathrm{O}_{11}$, calcd. 499.165, found 499.163.

$\boldsymbol{G l c}_{3} \boldsymbol{A A m}$. $N$-Propargyl acrylamide (29 $\left.\mathrm{mg}, 268 \mu \mathrm{mol}\right)$, $\mathrm{CuSO}_{4} \cdot 5 \mathrm{H}_{2} \mathrm{O}(5.3 \mathrm{mg}, 21 \mu \mathrm{mol})$, AscNa $(8.5 \mathrm{mg}, 43$ $\mu \mathrm{mol})$, and TBTA $(10 \mathrm{mg}, 19 \mu \mathrm{mol})$ were added to a $50 \%$ DMF aqueous solution ( $4 \mathrm{~mL}$ ) of $\beta$-maltotriosyl azide $(106 \mathrm{mg}, 200 \mu \mathrm{mol})$, and the resulting mixture was stirred for $3.5 \mathrm{~h}$ at room temperature. After concentration of the reaction mixture under reduced pressure, the product was purified by silica gel column chromatography $\left(\mathrm{MeCN} / \mathrm{H}_{2} \mathrm{O}=5 / 2\right)$ and then stirring with metal scavenger (SiliaMetS ${ }^{\circledR}$ Imidazole, $99 \mathrm{mg}$, 5 equiv. for $\mathrm{Cu}$ ) overnight at room temperature. After removing of metal scavenger by filtration, the filtrate was concentrated under reduced pressure and freeze-dried to give Glc 3 AAm (92 mg, $145 \mu \mathrm{mol}, 72 \%$ ). ${ }^{1} \mathrm{H}$ NMR (600 MHz, $\left.\mathrm{D}_{2} \mathrm{O}\right): \delta(\mathrm{ppm}) 8.08(\mathrm{~s}, 1 \mathrm{H}$, triazole), 6.24-6.13 (m, $2 \mathrm{H}$, vinyl), 5.73-5.68 ( $\mathrm{m}, 2 \mathrm{H}$, vinyl and $\mathrm{H} 1), 5.40\left(\mathrm{~d}, J_{1}{ }^{\prime},{ }^{\prime}=3.0 \mathrm{~Hz}, 1 \mathrm{H}, \mathrm{H} 1{ }^{\prime}\right), 5.33\left(\mathrm{~d}, J_{1}{ }^{\prime}, 2^{\prime},=\right.$ $3.6 \mathrm{~Hz}, 1 \mathrm{H}, \mathrm{H} 1$ '), 4.51 (s, 2H, N-CH 2 ), 3.96-3.32 (m, $\left.18 \mathrm{H}, \mathrm{Glc}_{3}\right) .{ }^{13} \mathrm{C}$ NMR $\left(125 \mathrm{MHz}, \mathrm{D}_{2} \mathrm{O}\right): \delta(\mathrm{ppm}) 168.6$ $(\mathrm{C}=\mathrm{O}), 144.9$ (triazole), 129.6 and 127.8 (vinyl), 123.0 (triazole), 99.8 and 99.5 (C1' and C1"), $86.4(\mathrm{C} 1), 77.4$ (C4), 76.7, 76.3, and 75.9 (C5, C-5', and C5'), 73.3 (C4'), 72.9, 72.7, and 72.1 (C3, C3', and C3'"), 71.7, 71.5, and 71.3 (C2, C2', and C2"), 69.3 (C4"), 60.5 and

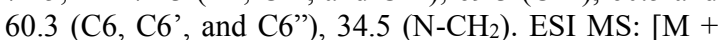
$\mathrm{Na}]^{+}, \mathrm{M}=\mathrm{C}_{24} \mathrm{H}_{38} \mathrm{~N}_{4} \mathrm{O}_{16}$, calcd. 661.218, found 661.217. Glc 5 AAm. $N$-Propargyl acrylamide $(22 \mathrm{mg}, 202 \mu \mathrm{mol})$, $\mathrm{CuSO}_{4} \cdot 5 \mathrm{H}_{2} \mathrm{O}(3.8 \mathrm{mg}, 15 \mu \mathrm{mol})$, AscNa $(6.5 \mathrm{mg}, 33$ $\mu \mathrm{mol})$, and TBTA $(7.8 \mathrm{mg}, 15 \mu \mathrm{mol})$ were added to a $50 \%$ DMF aqueous solution ( $3 \mathrm{~mL}$ ) of $\beta$-maltopentaosyl azide $(125 \mathrm{mg}, 146 \mu \mathrm{mol})$, and the resulting mixture was stirred for $5 \mathrm{~h}$ at room temperature. After concentration of the reaction mixture under reduced pressure, the product was purified by silica gel column chromatography $\left(\mathrm{MeCN} / \mathrm{H}_{2} \mathrm{O}=5 / 2\right)$ and then stirring with metal scavenger (SiliaMetS ${ }^{\circledR}$ Imidazole, $71 \mathrm{mg}, 5$ equiv. for $\mathrm{Cu}$ ) overnight at room temperature. After removing of metal scavenger by filtration, the filtrate was concentrated under reduced pressure and freeze-dried to give Glc ${ }_{5} \mathrm{AAm}(109 \mathrm{mg}, 113 \mu \mathrm{mol}$, $78 \%) .{ }^{1} \mathrm{H}$ NMR $\left(600 \mathrm{MHz}, \mathrm{D}_{2} \mathrm{O}\right): \delta(\mathrm{ppm}) 8.08(\mathrm{~s}, 1 \mathrm{H}$, triazole), 6.22-6.14 (m, $2 \mathrm{H}$, vinyl), 5.73-5.68 (m, $2 \mathrm{H}$, vinyl and $\mathrm{H} 1), 5.41\left(\mathrm{~d}, J_{1^{\prime}, 2^{\prime}}=4.2 \mathrm{~Hz}, 1 \mathrm{H}, \mathrm{H} 1^{\prime}\right), 5.33$ (s, $3 \mathrm{H}, \mathrm{H} 1$ ", $\mathrm{H} 1$ "', and $\mathrm{H} 1$ '"'), $4.51\left(\mathrm{~s}, 2 \mathrm{H}, \mathrm{N}-\mathrm{CH}_{2}\right)$, 3.95-3.32 (m, 30H, Glc 5$).{ }^{13} \mathrm{C}$ NMR $\left(150 \mathrm{MHz}, \mathrm{D}_{2} \mathrm{O}\right): \delta$ (ppm) $168.6(\mathrm{C}=\mathrm{O}), 144.9$ (triazole), 129.6 and 127.8 (vinyl), 123.0 (triazole), 99.7, 99.6, and 99.5 (C1', C1", C1"', and C1"'), 87.2 (C1), 77.4, 76.9, 76.8, 76.7, 76.3, 75.8, 73.3, 72.9, 72.7, 72.1, 71.7, 71.5, 71.2, 69.3, and $60.5\left(\mathrm{Glc}_{5}\right), 34.5\left(\mathrm{~N}-\mathrm{CH}_{2}\right)$. ESI MS: $\left[\mathrm{M}+\mathrm{Na}^{+}, \mathrm{M}=\right.$ $\mathrm{C}_{36} \mathrm{H}_{58} \mathrm{~N}_{4} \mathrm{O}_{26}$, calcd. 985.324, found 985.347.

$\boldsymbol{G l c} 7 \boldsymbol{A A m}$. $N$-Propargyl acrylamide $(6.0 \mathrm{mg}, 55 \mu \mathrm{mol})$, $\mathrm{CuSO}_{4} \cdot 5 \mathrm{H}_{2} \mathrm{O}(1.2 \mathrm{mg}, 5 \mu \mathrm{mol}), \mathrm{AscNa}(2.0 \mathrm{mg}, 10$ $\mu \mathrm{mol})$, and TBTA $(2.7 \mathrm{mg}, 5 \mu \mathrm{mol})$ were added to a $50 \% \quad$ DMF aqueous solution $(2.5 \mathrm{~mL})$ of $\beta$-maltoheptaosyl azide $(59 \mathrm{mg}, 50 \mu \mathrm{mol})$, and the resulting mixture was stirred for $5 \mathrm{~h}$ at room temperature. After concentration of the reaction mixture under reduced pressure, the product was purified by silica gel column chromatography $\left(\mathrm{MeCN} / \mathrm{H}_{2} \mathrm{O}=5 / 2\right)$ and then stirring with metal scavenger (SiliaMetS ${ }^{\circledR}$ Imidazole, 22 $\mathrm{mg}, 5$ equiv. for $\mathrm{Cu}$ ) overnight at room temperature. After removing of metal scavenger by filtration, the filtrate was concentrated under reduced pressure and freeze-dried to give $\mathrm{Glc}_{7} \mathrm{AAm}(50 \mathrm{mg}, 39 \mu \mathrm{mol}, 78 \%$ ). ${ }^{1} \mathrm{H}$ NMR $\left(600 \mathrm{MHz}, \mathrm{D}_{2} \mathrm{O}\right): \delta(\mathrm{ppm}) 8.08(\mathrm{~s}, 1 \mathrm{H}$, triazole), 6.25-6.14 (m, $2 \mathrm{H}$, vinyl), 5.73-5.68 (m, $2 \mathrm{H}$, vinyl and H1), 5.41 (d, $\left.J_{1^{\prime}, 2}{ }^{\prime}=3.6 \mathrm{~Hz}, 1 \mathrm{H}, \mathrm{H} 1^{\prime}\right), 5.33$ (s, 5H, H1', H1"', H1'"', H1"'”, and H1'"'"), 4.52 (s, 2H, N-CH2), 3.95-3.33 (m, 42H, Glc 7$) \cdot{ }^{13} \mathrm{C}$ NMR $\left(150 \mathrm{MHz}, \mathrm{D}_{2} \mathrm{O}\right): \delta$ (ppm) $168.6(\mathrm{C}=\mathrm{O}), 144.9$ (triazole), 129.6 and 127.8 (vinyl), 123.0 (triazole), 99.6 (C1', C1", C1"', C1'”,, C1"'”, C1"'"'), 87.2 (C1), 77.4, 76.8, 76.3, 75.9, 73.3, 72.9, 72.7, 72.1, 71.7, 71.5, 71.2, 69.3, and 60.4 (Glc 7), $34.5\left(\mathrm{~N}-\mathrm{CH}_{2}\right)$. ESI MS: $[\mathrm{M}+\mathrm{Na}]^{+}, \mathrm{M}=\mathrm{C}_{48} \mathrm{H}_{78} \mathrm{~N}_{4} \mathrm{O}_{36}$, calcd. 1309.429 , found 1309.443

\subsection{Synthesis of glycopolymers}

RAFT copolymerization reactions were carried out at $1.0 \mathrm{M}$ in total monomer concentration. AAm, the glycomonomer, $\mathrm{V}-70$, and BTSE were dissolved in 0.25 $\mathrm{mL}$ DMSO in a glass tube ([total monomer] $/[\mathrm{BTSE}] /[\mathrm{V}-70]=150 / 1 / 0.2)$. The feeding molar ratio of $\mathrm{AAm} /$ glycomonomer was $9 / 1$. The resulting solution was degassed by three freeze-thaw cycles, then the glass tube was sealed under vacuum and stirred at $35{ }^{\circ} \mathrm{C}$ for $24 \mathrm{~h}$. The products were purified by dialysis (Spectra/Por 7 MWCO 3500) against deionized water and freeze-dried to give glycopolymers.

PolyGlc $_{2} \boldsymbol{A A m} .{ }^{1} \mathrm{H}$ NMR $\left(300 \mathrm{MHz}, \mathrm{D}_{2} \mathrm{O}\right): \delta(\mathrm{ppm}) 8.05$ (triazole), 7.3-7.1 (Ph), $5.67(\mathrm{H1}), 5.37(\mathrm{H1}$ '), 4.38 $\left(\mathrm{N}-\mathrm{CH}_{2}\right), 4.0-3.3 \quad\left(\mathrm{Glc}_{2}\right.$ and $\left.\mathrm{S}-\mathrm{CH}_{2}-\mathrm{CH}_{2}-\right), 2.3-1.3$ $\left(\left(-\mathrm{CH}_{2}-\mathrm{CH}-\right)_{\mathrm{n}}\right)$.

PolyGlc $_{3} \boldsymbol{A A m} .{ }^{1} \mathrm{H}$ NMR $\left(300 \mathrm{MHz}, \mathrm{D}_{2} \mathrm{O}\right): \delta(\mathrm{ppm}) 8.12$ (triazole), 7.3-7.2 (Ph), $5.73(\mathrm{H} 1), 5.42\left(\mathrm{H}^{\prime}\right), 5.35$ (H1'), $4.43\left(\mathrm{~N}-\mathrm{CH}_{2}\right), 4.1-3.3\left(\mathrm{Glc}_{3}\right.$ and $\left.\mathrm{S}-\mathrm{CH}_{2}-\mathrm{CH}_{2}-\right)$, 2.4-1.3 ((- $\left.\left.\mathrm{CH}_{2}-\mathrm{CH}-\right)_{\mathrm{n}}\right)$.

PolyGlc5AAm. ${ }^{1} \mathrm{H}$ NMR $\left(300 \mathrm{MHz}, \mathrm{D}_{2} \mathrm{O}\right): \delta$ (ppm) 8.06 (triazole), 7.3-7.1 (Ph), 5.67 (H1), 5.37 (H1'), 5.30 (H1', $\mathrm{H} 1$ "', and $\mathrm{H} 1$ '"'), $4.39\left(\mathrm{~N}-\mathrm{CH}_{2}\right), 3.9-3.3$ (Glc5 and $\left.\mathrm{S}-\mathrm{CH}_{2}-\mathrm{CH}_{2}-\right), 2.3-1.3\left(\left(-\mathrm{CH}_{2}-\mathrm{CH}-\right)_{\mathrm{n}}\right)$

Poly Glc 7 A Am.${ }^{1} \mathrm{H}$ NMR $\left(300 \mathrm{MHz}, \mathrm{D}_{2} \mathrm{O}\right): \delta(\mathrm{ppm}) 8.12$ (triazole), 7.3-7.2 (Ph), $5.73(\mathrm{H1}), 5.42(\mathrm{H} 1$ '), 5.35 (H1", $\mathrm{H} 1$ '", $\mathrm{H} 1$ '"', $\mathrm{H} 1$ '"', and $\mathrm{H} 1$ '"'"'), $4.45\left(\mathrm{~N}-\mathrm{CH}_{2}\right), 4.0-3.3$ (Glc7 and $\left.\mathrm{S}_{-} \mathrm{CH}_{2}-\mathrm{CH}_{2}-\right), 2.4-1.3\left(\left(-\mathrm{CH}_{2}-\mathrm{CH}-\right)_{n}\right)$.

\subsection{Preparation and binding assay of glycopolymer-decorated GNPs}

The glycopolymer $(9 \mathrm{mg})$ and $\mathrm{NaBH}_{4}(3 \mathrm{mg})$ were dissolved in water $(0.1 \mathrm{~mL})$ and stirred for $1 \mathrm{~h}$ at room temperature. The reaction mixture was purified by dialysis (Spectra/Por 7 MWCO 3500) against deionized water, and the thiol-terminated glycopolymer was obtained by freezedrying. The resulting thiol-terminated glycopolymer $(1 \mathrm{mg})$ was dissolved in GNP suspension $(1 \mathrm{~mL})$ and shaken overnight in the dark. The solution was centrifuged in an ultracentrifuge $(100,000 \mathrm{~g}, 30$ $\mathrm{min})$. The resulting solid was washed with water, centrifuged in the ultracentrifuge, and freeze-dried to give glycopolymer-decorated GNPs. The resulting glycopolymer decorated-GNPs were dispersed in PBS $(2.5 \mathrm{~mL})$. The lectin solution was added to the GNP suspension and mixed thoroughly at room temperature, and then absorbance were recorded by a UV-Vis 
spectrophotometer.

Acknowledgements: This work was financially supported by JSPS KAKENHI Grant No. 25810075.

\section{REFERENCES}

[1] Y. C. Lee and R. T. Lee, Acc. Chem. Res., 28, 321-327 (1995).

[2] M. Mammen, S. K. Choi, and G. M. Whitesides, Angew. Chem. Int. Ed., 37, 2755-2794 (1998).

[3] J. M. de la Fuente, A. G. Barrientos, T. C. Rojas, J. Rojo, J. Canada, A. Fernandez, and S. Penades, Angew. Chem. Int. Ed., 40, 2258-2261 (2001).

[4] J. Rojo, V. Díaz, J. M. de la Fuente, I. Segura, A. G. Barrientos, H. H. Riese, A. Bernad, and S. Penadés, ChemBioChem, 5, 291-297 (2004).

[5] S. G. Spain, L. Albertin, and N. R. Cameron, Chem. Commun., 4198-4200 (2006).

[6] A. Housni, H. Cai, S. Liu, S. H. Pun, and R. Narain, Langmuir, 23, 5056-5061 (2007).

[7] O. M.-Ávila, L. M. Bedoya, M. Marradi, C. Clavel, J. Alcamí, and S. Penadés, ChemBioChem, 10, 1806-1809 (2009).

[8] V. Poonthiyil, P. T. Nagesh, M. Husain, V. B. Golovko, and A. J. Fairbanks, Chem. Open, 4, 708-716 (2015).

[9] E. K. Woller and M. J. Cloninger, Org. Lett., 4, 7-10 (2002).

[10] Y. M. Chabre and R. Roy, Curr. Top. Med. Chem., 8, 1237-1285 (2008).

[11] K. Tanaka, E. R. O. Siwu, K. Minami, K. Hasegawa, S. Nozaki, Y. Kanayama, K. Koyama, W. C. Chen, J. C. Paulson, Y. Watanabe, and K. Fukase, Angew. Chem. Int. Ed., 49, 8195-8200 (2010).

[12] M. Toyoshima, T. Oura, T. Fukuda, E. Matsumoto, and Y. Miura, Polym. J., 42, 172-178 (2010).

[13] J. Ishii, M. Toyoshima, M. Chikae, Y. Takamura, Y. Miura, Bull. Chem. Soc. Jpn., 84, 466-470 (2011).

[14] R. Sunasee and R. Narain, Macromol. Biosci., 13, 9-27 (2013).

[15] C.-C. Yu, L.-D. Huang, D. H. Kwan, W. W. Wakarchuk, S. G. Withers, and C.-C. Lin, Chem. Commun., 10166-10168 (2013).

[16] J. M. de la Fuente and S. Penades, Tetrahedron Asym., 16, 387-391 (2005).

[17] K. Niikura, S. Sekiguchi, T. Nishio, T. Masuda, H. Akita, Y. Matsuo, K. Kogure, H. Harashima, and K. Ijiro, ChemBioChem, 9, 2623-2627 (2008).

[18] T. Tanaka, H. Ishitani, Y. Miura, K. Oishi, T. Takahashi, T. Suzuki, S. Shoda, and Y. Kimura, ACS Macro Lett., 3, 1074-1078 (2014).

[19] T. Tanaka, Y. Zhou, C. Tamoto, Y. Kurebayashi, T. Takahashi, and T. Suzuki, J. Appl. Glycosci., 64, 43-48 (2017).

[20] T. Tanaka, H. Nagai, M. Noguchi, A. Kobayashi, and S. Shoda, Chem. Commun., 3378-3379 (2009).

[21] P. Wipf, Y. Aoyama, and T. E. Benedum, Org. Lett., 6, 3593-3595 (2004).

[22] M. Hales, C. B.-Kowollik, T. P. Davis, and M. H. Stenzel, Langmuir, 20, 10809-10817 (2004).

(Received May 18, 2017; Accepted June 27, 2017;

Published Online August 1, 2017) 